\title{
ГCOM \\ Exit only: harms from silencing employee voice
}

\section{Karen Adkins}

Abstract

\section{Keywords}

DOI
The nationwide shortage of PPE for health care workers has been well documented. Reporting on this issue has been complicated by hospitals' imposition of gag orders on physicians and health care workers. There are harms that result from imposing these gag orders that go beyond the obvious harms to public and employee health and safety. Using Hirschman's Exit, Voice, and Loyalty (1970) as a framework demonstrates that these orders represent a dangerous concentration of power in employer hands - health care workers are reduced to functionaries. Hirschman's argument, in part, is that organisations should seek to balance the availability of exit, voice, and loyalty for employees. Restricting employee options in morally untenable situations to exit only leads to direct and indirect harms. These gag orders are a pernicious practice, and bring with them long-term negative implications for employee morale, employee effectiveness, and public service.

Health communication; Science and policy-making

https://doi.org/10.22323/2.19050203

Submitted: 18th June 2020

Accepted: 12th August 2020

Published: 30th September 2020

Tara Roberson rightly praises a stakeholder model of public relations in science communication [2020], by contending that properly implemented, it can democratise communication and increase agency. A stakeholder model of public relations requires policy and infrastructure support to function, so that channels of communication stay open even in crises, and that stakeholders aren't punished for raising dissent. The COVID pandemic has demonstrated the ways in which top-down public relations restricts employee speech and dissent in ways that are counterproductive to employee rights and well-being. In this essay, I want to explore one specific way that hospitals and health-care companies in the United States are resorting to one-sided public relations, by silencing frontline health care workers' reporting of personal protective equipment (PPE) shortages. ${ }^{1}$ I will utilise Albert Hirschman's Exit, Voice, and Loyalty [1970] as the framework for my

\footnotetext{
${ }^{1}$ Some of the structural differences between labour policy and practice in the United States and elsewhere in the Global North limit the immediate application of this argument: worker rights and tribunals are vastly more limited in the U.S. than they are in most other developed countries, labour union membership has been rapidly declining in the U.S., etc. I would caution, however, that the
} 
analysis. ${ }^{2}$ My reading of Hirschman's text will focus on the relationship between the three employee reactions to morally problematic situations. I argue that his text implies the crucial value of employee options, plural, for responses to moral dilemmas at work. For employees to have the choice between speaking up, remaining silent, or leaving a company that is following questionable policies gives them meaningful stakeholder status in the workplace. Following this analysis, I will demonstrate that first, restrictions on employee speech reduces their autonomy in ways that are destructive to individual and corporate functioning. Reducing employee responses to intolerable situations by eliminating voice reduces individual employee effectiveness, has a 'chilling effect' on employee speech and contribution generally, and can negatively impact the reputation of the institution. At its core, I argue that suppressing employee voice is a way of guaranteeing short-term peace at the risk of longer-term turmoil and harms. Conversely, I will argue that Roberson's and Hirschman's essays make the case for the affirmative value of robust employee speech, even and especially in dissent. While there are complicating views I will consider in the course of this argument - the idea that whistleblowing brings with it moral hazards, and the particular hazards of employee voice in the age of social media - I still conclude that on balance, employee voice needs explicit protection and support.

\section{PPE shortages and employee silencing}

During the COVID-19 outbreak, the U.S. is experiencing a significant and prolonged shortage of personal protective equipment like gowns, gloves, or N95 masks. One phone survey of 323 hospitals throughout the United States and Puerto Rico in late March revealed "widespread" shortages of PPE [U.S. Department of Health and Human Services Office of Inspector General, 2020]. While PPE shortages no longer receive significant coverage in the press, the shortage in the U.S. appears to be ongoing [Bernstein and Safarpour, 2020]. Health care workers have begun using social media to call for contributions of PPE [Padilla, 2020]. Multiple press reports describe hospitals forcing employees to reuse PPE over several shifts [Leopold, Cormier and Templeton, 2020; Butler, 2020]. The particular effect this has on health care workers, who have very close contact with patients who may be carrying the virus, is clearly hazardous. Community transmission can be amplified in a health care facility, as a Pennsylvania nurse asserted after alleging that she was required to work in the NICU even after testing positive for coronavirus, amidst a delay in hospital supplies of PPE [Butler, 2020].

As a result of the nationwide shortage, doctors and nurses have started speaking up publicly about the need for PPE and the dangers of the shortage, which has had some effective systematic responses. In general, these leaks have been anonymous; employees cite fears of reprisal from the corporate owners of the hospital systems [Butler, 2020]. ${ }^{3}$ The VA hospital system in Los Angeles made their PPE equipment

economic appeal of reducing worker protections and privatizing public goods like health care has made inroads in other countries. Macklin and Spurgin's argument about employee speech limitations in Australia notes recent acts that have reduced employee rights [2007], and of course austerity practices in many European countries have in some instances led to employees' perception of lack of autonomy at work [see Humphries et al., 2019].

${ }^{2}$ While Hirschman's text is 50 years old, it has continually been applied and extended to analyses of worker rights and voice. For recent examples, see for instance Stoker [2005], Chen and Lai [2014], Hoffmann [2006], Humphries et al. [2019] and MacGregor and Stuebs [2014].

${ }^{3}$ Health care workers are starting to organize publicly to express their concern; several lawsuits have been filed and public protests have been organized over the PPE shortage and the danger it represents. See Chiu [2020]. 
policy more generous two days after employees anonymously leaked to Buzzfeed that they were permitted only one N95 mask per shift and were having to reuse masks, sometimes for a week [Leopold, Cormier and Templeton, 2020].

The improvements in PPE access and policy, however, have come at high costs for those employees who speak publicly and identifiably about the shortages. Ming Lin, who worked as an ER physician in a Bellingham (Washington) hospital, posted several times on Facebook from March 16 - 26 about limited access for PPE. He was fired March 27, and the rationale given by the hospital system's COO was that his comments constituted "[falsely] yelling fire in a crowded theater," and thus created a "toxic environment" [Judd, 2020]. A nurse in Chicago was fired by her hospital after emailing colleagues (not leaking to the press) about her request for more secure PPE [Carville, Court and Brown, 2020]. An obvious inference from these cases of termination and anonymous employee speech is that hospital management teams are proactively limiting employees' speech about the PPE through non-disparagement policies.

Non-disparagement clauses, also known as "gag orders", are common features of severance agreements between companies and employees. They are subject to controversy and ethical challenge; non-disparagement clauses have been shown to be used as an incentive to keep patterns of sexual harassment or discrimination quiet, for instance. ${ }^{4}$ But increasingly, some industries are using or imposing versions of gag orders for the continuity of employment, or in particular during a crisis at the workplace. There are many allegations of employee silencing during the COVID crisis in the United States. ${ }^{5}$ Bloomberg News names three hospital chains that preventively silenced health care workers from talking to the press, and a fourth that terminated an employee who spoke publicly [Carville, Court and Brown, 2020]. The Executive Director of the Washington State Nurses Association reports similar concerns coming from many members, who describe threats of firings if they speak to the press, or daily reminders about prohibitions of prohibitions against talking to the press [Watkins, 2020]. Nisha Mehta, a doctor who runs Facebook physician groups with over 60,000 members, reports hearing "widespread" stores from doctors across the country about silencing, with some receiving "daily emails urging them not to talk to the media under any circumstances" [Carville, Court and Brown, 2020]. When The New York Times contacted Mount Sinai employees about a nurse manager who had died of COVID after its documented equipment shortage, several said responded anonymously they'd been explicitly instructed by management not to speak to the press [Sengupta, 2020].

Hospitals offer a variety of rationales justifying the restrictions on employee speech. Most persuasively, hospital systems point to the shifting CDC guidelines about best PPE practices, particularly when it comes to safety practices around masks (whether or not to wear them in waiting rooms, for instance). They also

\footnotetext{
${ }^{4}$ They are also the subject of vigorous legal dispute and discussion. I will generally avoid these issues, as my focus is on their ethical challenges.

${ }^{5} \mathrm{My}$ argument could extend to other 'essential worker' companies like grocery chains and Amazon, which have both been consistently criticized for a failure to ensure worker safety during the COVID pandemic, and have appeared either to pre-emptively restrict employee speech about safety protocols, or to fire employees who do speak up. I am focusing here on health care workers in part because the public service orientation of health care is so widely recognized, making these silencing policies particularly pernicious.
} 
point out the risks of variant practices, and the need for consistency across cases [Richtel, 2020]. But neither of these rationales have direct bearing on restrictions of employee complaints about safety. In the U.S., the health care profession has explicit and additional legislative speech restrictions for reasons of patient privacy (HIPAA), and indeed HIPAA is cited by one hospital spokesperson as a reason for the gag orders. NYU Langone Health notified all employees that talking to the media without authorization could result in "disciplinary action, including termination," and their spokesperson's rationale justified this policy as a protection of patient and staff confidentiality [Carville, Court and Brown, 2020]. However, it seems unlikely that HIPAA liability is the driving factor here. In reporting PPE shortages, physicians and nurses are commenting on their own safety and protection as much as they are of patients, and neither commenting on nor revealing names or details of individual patient care. HIPAA governs the privacy of medical records; these health-care workers are speaking out about medical care policy.

It is hard to see that public image is not, in fact, the effective motivator in many of these policy decisions, policy reversals, and retaliations against employees who raise concerns. One immunocompromised doctor who wore masks in public areas of the hospital received an all-caps chastising text from his supervisor: "UR WEARING [a mask] DOWN A PUBLIC HALL. THERES [sic] NO MORE WUHAN VIRUS IN THE HALLS AT THE HOSPITAL THAN WALMART. MAYBE LESS"

[Richtel, 2020]. It is clearly the fact that the hall is public that has raised this supervisor's anger: 'public' is the only relevant modifier in the first sentence, and the hospital is explicitly compared to a Walmart. Absent the emphasis on 'public', the sentence does not seem worthy of a supervisor comment. The supervisor's concern in this text is about the impression of transmissibility and vulnerability. Concerns about image are emerge in many of these accounts. A spouse of a doctor in a different city posted on Facebook that hospital administration's concern was that public mask-wearing would "panic employees" [Richtel, 2020]. Still a third instance of open mask-wearing prompted an administrative email cautioning doctors not to "go rogue" with mask-wearing; "[t]hese are emotional times, and we need to control our emotions" [Richtel, 2020]. "Anything [you say] about the coronavirus or that we don't have enough equipment at the hospital, they're pulling you into the office," says one employee in a Pennsylvania hospital [Butler, 2020].

Given that these policies get promptly reversed after public exposure, these asserted rationales around consistency and panicking the public seem unlikely. In both the LA and Pennsylvania cases, policies around PPE availability for employees were revised within days of negative press coverage. In the LA case, the swift reversal of the position came with the medical director's acknowledgement of "failure on my part to effectively communicate with you so that each and every employee knows our operational status and what we're doing to keep you safe" [Leopold, Cormier and Templeton, 2020].

Framing the issue entirely as a failure of communication is misleading — it suggests that the initial failure was one of speech only, rather than a substantive or policy failure (a failure to anticipate equipment and employee needs). Additionally, the way in which the medical director describes communication is entirely top-down. His failure to communicate is in his failure to speak explicitly, rather than to listen and respond to employee concerns. Similarly, one of the Pennsylvania hospital 
employees notes that management's first response to his reports of complaints about safety is "What's the person's name?" which suggests a concern for identifying the source of the complaint rather than addressing the core issue [Butler, 2020]. Thus, while a variety of rationales are offered to defend gag orders, the effective rationale seems to be concern over hospital image. This is a deeply problematic practice, that is at odds with more productive models of workplace communication.

Exit, voice and loyalty
The flaws in this top-down silencing of employee voice can be illuminated by examining an older text about consumer choice. Albert Hirschman's Exit, Voice, and Loyalty [1970] frames a case about imperfect employee and customer choices in flawed and immoral markets primarily through the language of economics. But his argument ranges well beyond market analysis, to include a serious consideration of power dynamics in organisations, as well as the role of ideology in constraining employee choice. This is why his work has been widely applied and extended in discussions of workplace speech and practices in the 50 years since its publication. ${ }^{6}$ His contention that exit, voice, and loyalty are each complicated options for dissatisfied agents helps us to understand the indirect as well as direct benefits of greater employee voice, and to appreciate the costs of minimising or silencing employee voice. His basic contention is that in an unsatisfactory consumer situation, agents choose between exit (leaving the organisation), loyalty (remaining with the organisation) and voice (expressing their unhappiness with the goal of influencing change) [Hirschman, 1970, p. 4]. Importantly, Hirschman frames these two choices as in relation to one another, not in isolation - only in extreme (and generally undesirable) situations is one faced with only one choice. He notes that the voice option is explicitly political [1970, p. 15], and often costly — he describes it as "messy" and involving "heartbreak" [1970, pp. 16, 107]. Voice is necessarily risky and messy if it is to be a live option to check managerial excess; he reminds us of the danger of reducing voice to a performative or symbolic role only (pace the devil's advocate, which he caustically observes getting revived in the Johnson administration's debates around the bombing campaigns in Vietnam, [1970, p. 115]). Symbolic protest is impotent, a form of 'blowing off steam', rather than something that substantively effects or influences practice [1970, p. 124]. This clearly makes voice a less attractive option for efficiency-minded managers, particularly those who are responding to corporate or budget imperatives.

Exit, being a more narrowly economic and individual phenomenon, is relatively tidier than voice - one decides to stop purchasing the consumer good, patronising the business, or being a member of the organisation. But Hirschman wants us to be mindful of the fact that this tidiness comes at its own costs - the costs of leaving an organisation can be persistent, particularly when one's identity is bound up within the organisation. This argument is especially relevant for us here, because these options are not considered in isolation, but operate in relation to one another. What seems like the cleanliness of the exit option is so in part because it is a short-term option; it is less likely to have long-term, beneficial improvement on many systems because of its individualistic character. Hirschman observes that the

\footnotetext{
${ }^{6}$ See note 2 for selective citations. Hirschman's model has been adapted and complicated over the decades, specific examples of which I will provide in the endnotes, but the complications do not change what I see as the essential insight of the affirmative value of a balance between choices for economic, social and political well-being.
} 
no-raiding agreement between the AFL and CIO unions in 1955 was motivated by a recognition that over-reliance on the exit option (essentially, creating incentives to get unions to switch affiliation) had a net destructive effect on the growth and health of the trade union movement as a whole. He concludes from this instance that exit can get emphasised at the cost of preserving or enhancing voice [1970, p. 29]. Exit, as a primarily individual choice, is a more short-term economic option; voice, in part due to its intrinsically collective and political features, is longer-term in its implications. ${ }^{7}$

The third term Hirschman introduces, that of loyalty, gets a complicated treatment (compared to how it is popularly understood today, as uncritical devotion to an ideal or entity). ${ }^{8}$ Hirschman notes that the greater the attachment one has to an organisation or product, the more likely one is to exercise voice rather than peremptorily exit - one's identity is bound up with the organisation, one wants the organisation to succeed and thrive [1970, p. 77]. Loyalty "activates voice" [1970, p. 78]. In the example considered today, this point seems particularly resonant, as employee loyalty can take many and sometimes conflicting forms, as I will show in the next section.

Harms of silencing employee voice
Gag orders represent an unhealthy concentration of power on the employer side, and reduce health care workers to factotums. In a straightforward sense, we can see gag orders as a reduction of employee autonomy at the workplace. When voice is preemptively silenced, employees have fewer options to express or direct their ethical dissatisfaction with workplace practices. But I also want to focus on the kind of loyalty that voice is being sacrificed for in these cases. While on the surface we could appreciate a basic employer request for loyalty to the hospital (employers and management want the entity to survive and thrive), it seems more likely that the actions of these health care workers springs from loyalty to their profession - feeling a loyalty to the principles of the Hippocratic oath, their identity or the profession of health care, or the well-being of their patients. Ming Lin, for instance, explicitly references his "oath to do no harm" as obligating him to advocate for patient safety [Carville, Court and Brown, 2020]. Indeed, Hirschman reminds us that even employees or members who exit an organisation out of dissatisfaction can still feel loyalty and identity to the organisation after their exit [1970, p. 99]. One of the uncomfortable implications of this application of Hirschman is the fact that the short-term economic well-being of the hospitals is directly in tension with these long-term principles. Because supporting employee voice and dissent is indeed politically messy, long-term stability could come at a cost of short-term criticism and even economic damages. And indeed, this seems to be why the kind of loyalty that gets motivated in non-disparagement clauses and terminations seems to be of such a shortsighted type. As Hirschman contends, institutional loyalty is often invoked unhealthily: "loyalty-promoting institutions and devices are not only uninterested in stimulating voice at the expense of exit: indeed, they are often meant to repress voice alongside exit" [1970, p. 92, emphasis

\footnotetext{
${ }^{7}$ While it is certainly true that economic exit can be used as a political instrument - in the form of a publicized boycott, for instance - exit does not require this collective or political application. By contrast, voice's effectiveness is premised upon collective action - voice is addressed to audiences, and must be registered and responded to for change to occur.

${ }^{8}$ Jeremy Adelman rightly observes that of the three terms, loyalty gets the theoretically thinnest treatment in the text [2020].
} 
original]. Thus, the sort of non-disparagement practices and firings recounted here, and the effect of limiting both voice and exit as live options, aren't accidental consequences, but fully predictable and intentional per Hirschman's analysis.

Second, it is worth contemplating why Hirschman spends time on the interrelationship between exit and voice. The power and utility of these options comes in part because they are options, plural, and that they are held or exercised in relation to one another. When one speaks up, only to be ignored, the implied alternative is one of exit; a peremptory exit from an organisation absent any exercise of voice tends to arouse questions. Hirschman's argument is premised upon a clear view of members and employees as ethical agents, who can wield economic and political power both individually and collectively. Agents speak and act effectively (not just strategically) when they have meaningful, substantive choices. While Hirschman resists arguing for any Platonically ideal mix of exit and voice, in part because organisations are dynamic and turbulent, his explicit caution in this passage is directed towards management consolidation, warning managers not to "strip the members-customers of the weapons which they can wield" [1970, p. 124, emphasis added]. While 'weapons' is an antagonistic term, the meaning is clear: reducing choices for members or customers reduces their agency. When voice gets removed from the triad of possible responses to morally difficult situations, employees are left with a digital stay-or-leave choice, which represents a net loss of employee autonomy in the workplace. Losing autonomy here means losing the ability to participate meaningfully in work governance; employees become disposable elements of an unchangeable system. The stay-or-leave choice implicitly disallows any sense of the organisation as fungible, fallible, and receptive to or in need of stakeholder feedback for improvement. From the perspective of the worker, the organisation becomes an impenetrable monolith. ${ }^{9}$

This digital choice is popularly framed as a choice of loyalty - staying is an act of fidelity to the organisation - but Hirschman reminds us that folk conceptions of loyalty are not necessarily meaningful. ${ }^{10}$ He describes uncritical loyalty ("my country, right or wrong") as nonsensical "if it were expected that 'our' country were to continue forever to do nothing but wrong" [1970, p. 78]. While this statement is surely too strong for my representation of health care organisations, a weaker version of this statement is still defensible. Loyalty to an organisation that cannot publicly be criticized or challenged is a thin loyalty, based less on what the organisation does and more on what the organisation represents or signifies. ${ }^{11}$ But

\footnotetext{
${ }^{9}$ Part of the shift in doctors' ability to speak frankly may be structurally driven. One doctor observes that because doctors are more likely to be employees of corporate systems or groups, they have experienced a "loss of autonomy and a denigration [of authority]"[Richtel, 2020].

${ }^{10}$ To see a concrete example of this, note the full-page ad taken out in the Bellingham Herald shortly after PeaceHealth fired Dr. Lin [reproduced at Servais, 2020]. While Dr. Lin is unnamed in the ad, he seems clearly to be the "one physician" who sows "division" and "distrust" in a(n otherwise presumably unified) hospital system.

${ }^{11}$ To that end, it seems significant that Hirschman groups tribal organisations like tribes, nation, church, and families as examples of organisations that react strongly to voice, but for whose members exit is not an option [p. 121]. These organisations are also examples of groups where identity is strongly based on representation or signification, so while exit is theoretically an option for all of these groups, it is one that is comparatively rarely acted upon. Given that Hirschman uses national patriotism as an example of loyalty misconstrued, these two examples together indicate the tangled relationships between these three choices. Many commentators have indicated that loyalty is the least well fleshed out of the three concepts [see Adelman, 2020, for instance]; Hoffman in particular indicates ways in which loyalty can vary in intensity and origin based on ideology or sociality [2006,
} 
representation that has no substantive relationship to a corporation's actual activities and choices is a pretty flimsy basis for continued loyalty.

Lastly, it is important to consider the implications of voice and exit as they apply to public goods (for while the hospitals in these articles are generally privately managed, health care is a public-goods sector of the economy). Hirschman rightly draws a distinction between pure marketplace thinking about the balance between exit and voice (when it comes to competitive choice about purchasing consumer goods of varying quality and price, e.g.), but notes that in cases where the balance is between a privately and publicly offered good (his example is education), there is a greater, not lesser, need for a balance of alternatives [1970, p. 52]. This balance, Hirschman makes clear, should be tilted in favor of voice rather than exit when the public interest is at stake; "if active concern with the public happiness can on occasion be felt as a benefit. . .then voice will have an occasional edge over exit in those situations that clearly impinge on the public happiness" [1980, p. 434]. Because public-goods choices are more impactful than purely individual consumer choices, the choice here between exit and voice carries with it steeper emotional and social costs than a purely economic failure; "the member will compare. . . the disutility, discomfort, and shame of remaining a member to the prospective damage which would be inflicted on him as a prospective nonmember and on society at large by the additional deterioration that would occur if he were to get out" [1970, p. 103, emphasis added]. Loyalty can be especially perverted in public-goods sectors because of these pressures; not only can managers utilize public loyalty to members or employees, but the viability of the exit option is deteriorated, as one's ability to influence an organisation only wanes once one has left the organisation [1970, p. 104]. Because identities are not univocal, and can be multiple (as I suggest is the case with health care workers), exiting one identity does not automatically diminish the need to exercise voice [Hirschman, 1980, p. 444]. Thus, employee voice should be more protected in public-goods sectors like health care than other sectors of the economy. And yet in the COVID crisis, the opposite has seemed to be the case. This failure to protect employee speech is damaging both to individual employees and the collective well-being of the company, which I will now review.

Direct and indirect harms of employee silencing
There are clear harms to this kind of employee silencing in a health care world. Most basically, there is a straightforward risk to public and employee health. COVID is very contagious, health care workers see many patients, and inadequate PPE increases the exposure of employees to COVID and the likelihood of community spread. ${ }^{12}$ Disallowing employee communication about vital equipment shortages makes it more likely that the shortages will continue, and thus imperil public health. However, in this discussion, I am more interested in iterating the kinds of workplace harms that seem inevitable with excessive and unjustified restrictions on employee speech, both in this crisis and for the long-term. I describe these harms as indirect because while there are reasonable short-term reasons for employers to want non-disparagement clauses in the workplace, Hirschman's analysis encourages us to think about the long-term implications of these

pp. 2328-2329]. Stoker [2005, p. 273] gives an account of passive loyalty that looks more like "grudging submission" and would thus not be very substantive.

${ }^{12}$ The Centers for Disease Control [2020] describes COVID-19 as easily and sustainably spread; Zhang et al. [2020] demonstrate that the disease is both airborne (and thus highly transmissible) and highly virulent. 
short-term policies. If companies are disinclined to respond to ethical appeals, one would hope that at minimum, long-term economic self-interest might motivate them. Hirschman's dry analysis of the need for both voice and exit as live corporate options appeals to long-term thinking and disparages the short-term tendencies of management: " $[w]$ hile feedback through exit or voice is in the long-run interest of organization managers, their short-run interest is to entrench themselves and to enhance their freedom to act as they wish, unmolested as far as possible by either desertions or complaints of members. Hence management can be relied on to think of a variety of institutional devices aiming at anything but the combination of exit and voice which may be ideal from the point of view of society" [1970, pp. 92-93]. I will show the long-term benefits of facilitating employee voice, but let me iterate at least three categories of harm here: to silenced employees individually, to employees collectively, and to the institutions reputationally. I review these sequentially, because it seems to me that the individual harms lead to and reinforce the collective and mission-focused harms.

Employees individually. Forcing employees to choose between their continued employment and adherence to their professional, public-health code, is a stark choice, and it imposes costs on employees who choose to raise ethical concerns. Health care workers who have blown the whistle on ethically problematic practices have faced professional reprisal and retaliation, which obviously has direct professional and material effects on their well-being [Ahern, 2018, p. 60]. The starkness of this choice also has emotional effects; one study of nurses who were retaliated against after whistleblowing recounts a whole host of emotional effects including anxiety, distress, grief, and symptoms of PTSD [Ahern, 2018, p. 60]. These effects are not just character impacts but professional-identity impacts; they are damaged as competent workers. ${ }^{13}$ The meaning and significance of professional identities, oaths, and institutional standards corrode when ethical appeals are met with retaliation rather than engagement [Ahern, 2018, pp. 61-62]. Gag orders signify that medical professionals are hired for their technical skills only, and that their value comes in their compliant delivery of technical services.

While ethical applications of Hirschman's argument tend to focus on the harms of exercising exit or voice, it is also clear that there are costs of compromised loyalty; that is, staying silent out of necessity because the organisation has imposed a gag order. The psychological costs of remaining silent in the face of injustice have been demonstrated elsewhere in the literature [Perlow and Williams, 2003; Cortina and Magley, 2003]. But I would posit that these harms have an ethical dimension alongside the psychological impacts. Workers who describe themselves as alienated from and resentful of their colleagues and supervisors of necessity see themselves as having less agency in their workplace. Jean Harvey [1999] describes this as restricting employees from full functioning in a workplace [1999, p. 111]. Soft-skills professions like health care, that rely so heavily on collaborative analysis, want to empower rather than restrict employee contribution.

\footnotetext{
${ }^{13}$ To be sure, employees who can prove retaliatory firing after justified whistleblowing have access to tort redress, but this is both a post hoc remedy, and one that is clearly not available to all employees (one has to have the means to hire a lawyer). And most basically, the harm done to workers as workers cannot be undone even with a legal judgment; their careers and competence have still been damaged without cause.
} 
Some of the administrator behaviour documented in these articles goes beyond simply devaluing employees as technicians only, to a more active and insidious denigration of their analytic and perceptive competence: a kind of crisis-induced gaslighting. Consider the heated texts and messages health care workers reported about the wearing of PPE in public halls, or discussing PPE shortages.

Administrators accused health care workers of being "emotional," causing panic, or falsely shouting fire in a crowded theatre. These are all versions of credibility-diminishment, telling medical professionals that their immediate, ground-level perceptions of a health care situation are not to be trusted.

Gaslighting, a kind of epistemic injustice that involves telling agents they are epistemically unreliable, has indirect harms, particularly in the workplace - it reduces creativity and engagement [Abramson, 2014; Adkins, 2019].

Employees collectively. Liberal commentators on speech and censorship have pointed out the indirect harms to all speakers on soft or firm restrictions on speech. Put plainly, there is a clear "chilling effect" on speech and dissent, whether or not the restriction on speech is hard (in the form of clear non-disparagement policies and retaliatory firing) or soft (shaming and discouragement). ${ }^{14}$ The message sent to employees is that authority must be adhered to and respected. Olivia Dixon [2018] offers the legal analysis here, noting that "the practical effect of including overly broad confidentiality undertakings in corporate agreements is to potentially chill employees who may otherwise provide information to regulators about potential corporate misconduct" [2018, pp. 445-446]. David Yamada [1998] describes some of the economic and policy pressures that can act as informal chills on employee speech; even theoretical commitments to employee freedom of speech can ring hollow when worker protections are few, or when industries are in economic turmoil. Rob Macklin and Earl Spurgin provide empirical data in support of this analysis [2007]. Their qualitative analysis of employees in Australian workplaces find that even with ostensive support for employee speech, many employees perceive a gap between their right to speak up at work, particularly in dissent, and their actual capacity to do so. Employees often perceived punishment for colleagues who raise contrary views and describe silencing their inner dissents out of fear of reprisal. When employees recognize that dissent is explicitly or implicitly discouraged, they would be more likely, it seems, to second-guess their ideas and contributions in a workplace.

Making employee options fewer and starker makes it more likely to have crisis-point interventions and eruptions, as opposed to a more continuous feedback loop from informed and experienced stakeholder employees. While non-disparagement clauses may seem prudent for efficiency-minded managers of all sorts of industries (and there is some indication that they are being more widely implemented throughout employment, and not merely at severance), they impose a structural restraint on all employees, and emphasize rather than reduce the gulf between labour and management. ${ }^{15}$ This seems particularly freighted in a public-goods industry like health care. ${ }^{16}$ Indeed, scholars of nursing ethics worried

\footnotetext{
${ }^{14}$ The classic framing of this argument comes from John Stuart Mill's On Liberty [1859], but it has been consistently reappropriated and adapted by legal and social theorists in the intervening years.

${ }^{15}$ Companies' increasing reliance on nondisparagement or noncompete clauses at severance, often to the point of absurdity, is a way in which companies can structurally and economically disincentivise the role of employee communication and trust [Preston, 2016].

${ }^{16}$ In extreme cases, as Humphries et al. note with their interviews of doctors, signifcant job dissatisfaction can result in actions beyond company exit such as profession or country exit.
} 
about exactly such an outcome in the early days of health care consolidation. One of the limitations with even a well-constructed whistleblower system is that it is overly focused on compliance and retroactivity. Some nursing ethicists described the newly developed whistleblowing code for nurses as a framework that would "work reasonably well for an HCO that is already committed to ethical behavior towards patients and staff; however, they fail to ensure commitment to an ethical climate from HCOs that are only seeking to fulfill the letter of the law" [Fletcher, Sorrell and Silva, 1998]. A "compliance only" approach to health care ethics from the management side ensures the continuation of morally untenable practices, with periodic and dramatic public eruptions. By contrast, a more consistent workplace culture that encourages and facilitates employee feedback, even if critical, would be more stable for ensuring productivity and morale. Indeed, Tara Roberson's defense of the value of public relations for science communication relies upon a robust, stakeholder view of public relations to result in communication that is "truly participative and not another form of deficit model outreach" [2020]. Roberson's tart observation here is that all too often, public relations is used as a kind of periodic image clean-up work after a crisis (the "deficit model"); it is disconnected to any broader view of connection and engagement with a diverse stakeholder public. It seems clear to me that this 'compliance only' approach follows this deficit model - only speak publicly when it is absolutely required, say the minimum, and try to move public attention along and away from the mistakes. Not only is this model insufficient for public communication, it minimizes accountability for the organisation itself.

In particular, if accountability within health care is understood to be accountable to one's patients first and primarily, whistleblowing when grave safety harms are ignored or denied, as with PPE shortages, would be clearly morally justified. And yet, if the system is designed to minimize professionals' ability to raise these concerns absent significant harm to their careers, it puts excessive pressure on ground-level healthcare professionals to do all the ethical heavy-lifting on behalf of, and indeed in opposition to, management. Fletcher et al.'s analysis points to the accountability failure at the heart of professional codes of nursing and medicine; they do not provide any structural support for health care professionals facing morally untenable situations. I would extend this analysis towards those in health care management and supervision; there is too little accountability for those groups. This raises the moral stakes for employees who witness problematic safety practices in an environment that discourages disclosure. Front-line health care workers are thus left carrying all the ethical burdens of the practices, taking the risks, and bearing the costs, to the exclusion of management.

Reputation of health care institutions. While it is certainly reasonable for companies in general to be concerned about bad publicity, overly stacking policy in favor of corporate communication and against ground-up communication has indirect effects, particularly in public-service professions like health care. Kathy Ahern's research about nurses who whistleblow demonstrates exactly this danger; nurses experience a sense of professional and institutional betrayal [2018]. Cynicism towards a company can be demoralizing; one of the VA hospital leakers in the Los Angeles case responded to the abrupt and prompt reversal on PPE policy by saying, "that level of honesty surprised me" [Leopold, Cormier and Templeton, 2020]. When employees are "surprised" that a company spokesperson publicly and 
directly acknowledges failure, this is deeply problematic. It suggests that the default expectation is for companies to stay silent about failures. Bioethicist Glenn Cohen observes that "when health-care workers say they are not being protected, the public gets very upset at the hospital system" [Carville, Court and Brown, 2020]. The irony of a hospital system that does not aggressively move to reverse practices known to imperil community and employee health is not slight, and indicates the importance of enhancing and safeguarding employee voice rather than minimising it, for the good of the institution. ${ }^{17}$ Put plainly, increased employee agency is in the long-term interest of the well-being of health-care institutions. Institutions that lose any sense of collective trust and goodwill, whether from patients, employees, or the public at large, will themselves struggle.

Because, as I have contended, health care workers feel mixed loyalties - to their professional duties as much as if not more than to their place of employment - silencing employees would provoke more public damages. One of the unanticipated blowbacks to gag orders is that, in this sort of time-sensitive situation, employees will increasingly pursue riskier and even more damaging ways of speaking up, like anonymous whistleblowing to the press or social media posts. We see clear evidence of this with the case of Ming Lin. In his first letter to his supervisor (posted on Facebook March 17, the day he sent it), his very first concern is that "[w]e have no line to express our concern about our safety other than thru you. . . [the CEO and CMO] are not interested in our concern." It seems clear he is turning to Facebook because internal channels have been pursued without effect. Internal voice that is ineffectively supported or perceived to be suppressed, whether in the form of a 'devil's advocate' or a rigidly adhered to chain of command, is damaging if the effect appears to be that significant concerns do not get traction at levels where action can be taken. More extreme and public revelations of risky policy can lower the long-term reliability and reputation of companies or industries.

The value of employee voice
These are the major harms that gag orders can have on employees. But I want now to shift the argument by briefly making the case for the benefits of fuller employee voice. Gag orders implicitly frame employee voice as presumptively and exclusively negative. By contrast, it is worth contemplating employee voice as a substantive good of an organisation - a sign of health. Following Hirschman's and Roberson's logic, I want to emphasize the affirmative value of employee voice as an intrinsic component of good organisations, and something that ought to be safeguarded rather than degraded. Speaking up, whether formally or informally, should be valuable to companies because it permits more insight and input into decisions and practices. Roberson notes that effective stakeholder communication, when well-structured, can promote long-term benefits of equity [2020]. Diverse voices and marginalised communities can be brought into conversations about organisations' work and missions. On an even more pragmatic level, it seems clear that there are consistent benefits to empowering employee feedback in the functionality of a workplace. When there are clear divisions between the kinds of

\footnotetext{
${ }^{17}$ Hirschman himself recognizes this sort of thinking when he comments, with respect to Britain's National Health Service, that the NHS should discourage exiting the system because it needs its dissatisfied members "as critics within the service" [1980, p. 451]. For NHS to improve its performance, it needs critics who feel validated in exercising their voice. Giving the dissatisfied an absolute stay-or-go choice is a way to ensure stagnation in quality.
} 
work that managers and employees do, employee feedback can be crucial to recognizing when a plan is missing a crucial component, or a supply-line is short, or a relevant community's needs or interests have not been taken seriously. This seems particularly true when there is not just a divide but a gulf between the work management does and that of its ground-level workers. William Gorden makes precisely this case when he notes that voice can be seen as "trying to correct activities and/or purify an image of the employing organization; that correcting may entail argument and negotiation, coalition formation, and even destructive subverting communication" [1988, p. 285]. Gorden's point is that while the tone or tenor of the communication may be negative or destructive, the aim is fully constructive: improving the quality of the organisation; as he states it, "[d]ignity and respect for all employees is thereby affirmed by enabling workers a genuine say about their jobs" [1988, p. 287, emphasis original]. Kevin Stoker's exploration of loyalty argues that whistleblowing can be a form of substantive loyalty, because one would only take the step of speaking out publicly because of a belief that the organisation is capable of change [2005, pp. 271-272]. Most basically, Perlow and Williams' research with executives cautions management not to discourage speaking up for reasons of sheer productivity; "each time workers remain silent in the face of conflict, they keep new ideas to themselves and leave alternative courses of action unexplored. And they withhold important information from colleagues that could enhance the quality of both their own and the organization's work" [2003]. This ethical harms of this inefficiency would be only exacerbated in a public-goods field like health care. What may seem to a manager's perspective to be negative or destructive criticism may in fact be important feedback that should not be preemptively stifled. To be specific, Kathryn Waddington's study of gossip in the nursing profession [2012] concludes that gossip can be an effective early warning system of trouble or problems in the workplace [2012, p.133]; to be clear, 'trouble' here does not just mean dissatisfied employees looking to sow dissent (the conventional imputation of gossip), but structural or workplace challenges that are being recognized on the ground floor but as yet invisible to management.

Waddington concludes her study by recommending that managers actively seek out and attend to employee gossip, as it helpfully signifies areas of weakness and low morale in the workplace. Hirschman is clear that the exercise of voice requires a channel for its internal reception and an opportunity for its application: "[v]oice has the function of alerting a firm or organization to its failings, but it must then give management, old or new, some time to respond to the pressures that have been brought to bear on it" [1970, p. 33]. Protecting and promoting employee voice, while bringing with it the likelihood of short-term dissent, is actually a surer path towards longer-term company and employee health and well-being.

The hazards of whistleblowing
I want to pause to consider objections to this view, of which there seem to be at least two. First is the idea that whistleblowing is not as straightforwardly positive as my argument renders it. While most of the literature on whistleblowing presents is as morally justified, some scholars have raised qualms about its use and overuse. Sissela Bok [1989] reminds us that whistleblowing is often seen as a breach of loyalty [1989, p. 214], can be done from mixed or selfish motives (such as bias or revenge [1989, p. 216]), and can be done disproportionately, by publicly magnifying a relatively minor problem [1989, p. 219]. Patrick O'Sullivan and Ola Ngau [2014] challenge the assumption that whistleblowers have epistemic and moral clarity 
about their judgments of the facts of their cases and the moral merit of whistleblowing.

These are serious concerns. ${ }^{18}$ As Hirschman himself notes [1970, p. 31], excessive or inapt use of voice can be counterproductive or publicly alarming. And while empirical evidence points to whistleblowers usually making multiple attempts at expressions of internal voice before going public [Miceli, Near and Dworkin, 2008], the fact remains that public whistleblowing makes situations more fraught, and can result in more chaotic, rather than less chaotic, results and communication. But these objections bear less well on this particular situation. First, the increased urgency of public voice when the problem being raised is both time-sensitive and has broad public impact. COVID is a fast-moving and extremely contagious disease, which makes PPE shortages particularly perilous. Hierarchical chains of command, particularly if protracted, can be cumbersome in a crisis - it seems clear that public complaints in several of these instances were exactly what motivated concrete improvements in PPE provision. Second, there's at least some reason in these cases to doubt that vigorous internal supports of employee voice exist (or at least, exist systematically and with meaningful reciprocity). Ming Lin's Facebook posts include several letters sent up the chain to executives (CEO, CMO, COO) on March 16 and 17, with Lin indicating both a prior absence of response and rigid hierarchy (noting that he was only authorized to communicate with an immediate supervisor). At least in this case, it appears that attempts to communicate internally were ignored. Indeed, the interview that COO Richard DeCarlo gives on YouTube on April 4 acknowledges the absence of communication, but reframes the issue. He regrets management not giving more information earlier, but says that they were too busy in a pandemic to "stage a media campaign" [Damania, 2020]. This conveniently reframes the issue as an easy false dichotomy; if the only two choices are managing an international pandemic or staging a media campaign, and if they cannot be accomplished simultaneously, this is an easy choice. ${ }^{19}$ The fallacy here seems clear, particularly in a healthcare structure that boasts a 14-member executive leadership team, in addition to nine public relations employees across the network. ${ }^{20}$ Indeed, while granting every bit of merit to these objections to whistleblowing as automatically virtuous that can be granted, I would suggest that in some ways, the worries about whistleblowing demonstrate the urgency and merit for robust internal protections of employee speech and dissent. Whistleblowing is and should remain a last resort; in companies that practice and protect stakeholder models of communication, whistles should not need to be blown.

The second objection draws from the fact that Hirschman's text was written in 1970, well before the onset of the age of social media. It is one thing to empower employee voice and dissent in 1970, but a very different and riskier proposition in 2020. In the age of social media, empowering employee voice can result not in a healthy diversity of discussion but in a cacophonous babble of competing voices

\footnotetext{
${ }^{18}$ Although I agree with Guy Thomas' assessment that altruistic motivation is "incidental but inessential" in whistleblowing; while mixed motives like bias or revenge may well occur in whistleblowing, they do not automatically invalidate the act [2020, p. 6].

${ }^{19}$ This comment is ironic in the midst of a pandemic, made by the $\mathrm{COO}$ as he gives a 45 -minute interview to a YouTuber [Damania, 2020], and after the health care system pays for a full-page ad in the April 5 edition of the Bellingham Herald to protest their treatment and the "division" in the community caused "by the opinions of a single physician."

${ }^{20}$ For the PR team, see https:/ / www.peacehealth.org/news/media-contacts. For the overall executive leadership, see https:/ / www.peacehealth.org/executive-leadership.
} 
and agendas, with little strategic direction. ${ }^{21}$ The merit of the stakeholder model of public relations, for instance, can be undermined if dissent is too easily raised immediately and confusingly online. The existing literature on social media and health care ethics mainly seems to focus on issues around individual patient privacy [see Brous and Olsen, 2017; Cain, 2011, for representative examples], which does not bear on the brunt of the argument here. However, it is certainly the case that the temptation to raise a concern online, instantly and in a crisis situation like a pandemic, brings with it some real dangers (less fact-checking, fewer internal checks, greater likelihood of confusion and credibility damages to both the whistleblower and the institution). But again, this seems to me to be a roundabout argument for reinforcing and buttressing employee voice in the health-care workplace. The literature on health-care whistleblowers demonstrates the likelihood that they experience formal or informal retaliation [McDonald and Ahern, 2000], which suggests strong implicit reasons to avoid whistleblowing if at all available. Given that employees who have organisational commitment and anticipate retaliation are more likely to whistleblow internally rather than externally [Chen and Lai, 2014, p. 335], it seems that reinforcing and supporting robust protections for employee dissent is actually a good means of whistleblowing prevention. Dissent that is handled internally will not migrate to social media posts and rants.

\section{Conclusion}

\section{References}

While it is clear that there are short-term benefits for hospitals and HCOs in keeping tight limits on employee speech, particularly during a crisis, my analysis suggests that there are a host of indirect harms and longer-term turbulence caused by this practice (in addition to the manifest and straightforward threat to public health). Restricting employee choices and diminishing employee voice in a morally unsatisfactory workplace strips employees of agency and autonomy in the workplace. Additionally, there is a 'chilling effect' for employees overall that reduces contribution and creativity at the workplace, and the reputation of health-care institutions suffers as they concentrate power in the hands of management. A quote from one Pennsylvania nurse crystallizes the dangers of restricting employee speech in the name of company well-being: "[t]his place actually makes you second-guess your career choice. . . [my] biggest concern. . . [is] at the end of the day, did I give my best care possible? And this place prevents you from doing that" [Butler, 2020, emphasis added]. Implementing a policy that makes a hardworking nurse, in the middle of a pandemic, question their choice of career and see their hospital as opposed to the practice of health care, is pernicious.

Abramson, K. (2014). 'Turning up the lights on gaslighting'. Philosophical Perspectives 28 (1), pp. 1-30. https://doi.org/10.1111/phpe.12046.

Adelman, J. (29th July 2020). 'Listen closely: “exit, voice and loyalty" @50'. Public Books. URL: https://www.publicbooks .org/listen-closely-exit-voice-and -loyalty-50/.

Adkins, K. C. (2019). 'Gaslighting by crowd'. Social Philosophy Today 35, pp. 75-87. https://doi.org/10.5840/socphiltoday201971660.

Ahern, K. (2018). 'Institutional betrayal and gaslighting: why whistle-blowers are so traumatized'. The Journal of Perinatal \& Neonatal Nursing 32 (1), pp. 59-65. https://doi.org/10.1097/jpn.0000000000000306.

\footnotetext{
${ }^{21}$ I thank an anonymous reviewer of an earlier draft for raising this meaningful objection.
} 
Bernstein, L. and Safarpour, A. (20th May 2020). 'Mask shortage for most health-care workers extended into May, Post-Ipsos poll shows'. The Washington Post. URL: https://www . washingtonpost.com/health/mask-shortage-for-mos t-health-care-workers-extended-into-may-post-ipsos-poll-shows/2020 /05/20/1ddbe588-9a21-11ea-ac72-3841fcc9b35f_story.html.

Bok, S. (1989). Secrets: on the ethics of concealment and revelation. Original publication year (1983). New York, NY, U.S.A.: Vintage.

Brous, E. and Olsen, D. P. (2017). 'Lessons learned from litigation: legal and ethical consequences of social media'. AJN, American Journal of Nursing 117 (9), pp. 50-54. https://doi.org/10.1097/01.naj.0000524546.50943.9e.

Butler, D. (11th April 2020). 'Anguished nurses say Pennsylvania hospital risked infecting cancer patients, babies and staff with Covid-19'. The Washington Post.

URL: https://www . washingtonpost.com/health/2020/04/11/amid-chaos-ang uished-nurses-say-pennsylvania-hospital-risked-infecting-cancer-pat ients-babies-staff/.

Cain, J. (2011). 'Social media in health care: the case for organizational policy and employee education'. American Journal of Health-System Pharmacy 68 (11), pp. 1036-1040. https://doi.org/10.2146/ajhp100589.

Carville, O., Court, E. and Brown, K. V. (31st March 2020). 'Hospitals tell doctors they'll be fired if they speak out about lack of gear'. Bloomberg News.

URL: https://www . bloomberg. com/news/articles/2020-03-31/hospitals-te ll-doctors-they-ll-be-fired-if-they-talk-to-press.

Centers for Disease Control (16th June 2020). How COVID-19 spreads. URL: https://www.cdc.gov/coronavirus/2019-ncov/prevent-getting-sick /how-covid-spreads.html.

Chen, C.-P. and Lai, C.-T. (2014). 'To blow or not to blow the whistle: the effects of potential harm, social pressure and organisational commitment on whistleblowing intention and behaviour'. Business Ethics: A European Review 23 (3), pp. 327-342. https://doi.org/10.1111/beer.12053.

Chiu, A. (21st April 2020). "We're beyond angered': fed-up nurses file lawsuits, plan protest at White House over lack of Coronavirus protections'. The Washington Post. URL: https://www . washingtonpost. com/nation/2020/04/21 /nurse-protection-coronavirus/.

Cortina, L. M. and Magley, V. J. (2003). 'Raising voice, risking retaliation: events following interpersonal mistreatment in the workplace'. Journal of Occupational Health Psychology 8 (4), pp. 247-265. https://doi.org/10.1037/1076-8998.8.4.247.

Damania, Z. (2020). The truth about our COVID preparedness (with Peacehealth's Richard DeCarlo). [Video interview]. URL: https://zdoggmd.com/richard-decarlo/.

Dixon, O. (2018). “Pretaliatory' enforcement action for chilling whistleblowing through corporate agreements: lessons from North America'. Federal Law Review 46 (3), pp. 427-453. https: //doi .org/10.1177/0067205x1804600304.

Fletcher, J., Sorrell, J. and Silva, M. C. (1998). 'Whistleblowing as a failure of organizational ethics'. Online Journal of Issues in Nursing 3 (3). URL: https://oji n. nursingworld.org/MainMenuCategories/ANAMarketplace/ANAPeriodicals /OJIN/TableofContents/Vol31998/No3Dec1998/Whistleblowing.html.

Gorden, W. I. (1988). 'Range of employee voice'. Employee Responsibilities and Rights Journal 1 (4), pp. 283-299. https://doi.org/10.1007/bf01556937.

Harvey, J. (1999). Civilized oppression. Lanham, MD, U.S.A.: Rowman \& Littlefield. 
Hirschman, A. O. (1970). Exit, voice and loyalty: responses to decline in firms, organizations and states. Cambridge, MA, U.S.A.: Harvard University Press.

- (1980). "Exit, voice and loyalty": further reflections and a survey of recent contributions'. The Milbank Memorial Fund Quarterly. Health and Society 58 (3), pp. 430-453. https://doi.org/10.2307/3349733.

Hoffmann, E. A. (2006). 'Exit and voice: organizational loyalty and dispute resolution strategies'. Social Forces 84 (4), pp. 2313-2330. https://doi.org/10.1353/sof .2006.0093.

Humphries, N., McDermott, A. M., Conway, E., Byrne, J.-P., Prihodova, L., Costello, R. and Matthews, A. (2019). "Everything was just getting worse and worse': deteriorating job quality as a driver of doctor emigration from Ireland'. Human Resources for Health 17 (1), 97. https://doi.org/10.1186/s12960-019-0424-y.

Judd, R. (6th April 2020). 'Bellingham hospital confirms firing ER doctor who criticized its Coronavirus response'. The Seattle Times. URL: https://www . seattI etimes.com/seattle-news/health/bellingham-hospital-confirms-firinger-doctor-who-criticized-its-coronavirus-response/.

Leopold, J., Cormier, A. and Templeton, J. (13th April 2020). 'A Veterans hospital changed its Coronavirus mask policy after employees complained'. Buzzfeed News. URL: https://www . buzzfeednews . com/article/jasonleopold/a-vetera ns-hospital-changed-its-coronavirus-mask-policy.

MacGregor, J. and Stuebs, M. (2014). 'The silent Samaritan syndrome: why the whistle remains unblown'. Journal of Business Ethics 120 (2), pp. 149-164. https://doi.org/10.1007/s10551-013-1639-9.

Macklin, R. and Spurgin, E. (2007). 'Free speech in the workplace'. Australian Journal of Professional and Applied Ethics 9 (1), pp. 101-113.

McDonald, S. and Ahern, K. (2000). 'The professional consequences of whistleblowing by nurses'. Journal of Professional Nursing 16 (6), pp. 313-321. https://doi.org/10.1053/jpnu.2000.18178.

Miceli, M., Near, J. and Dworkin, T. M. (2008). Whistleblowing in organizations. New York, NY, U.S.A.: Psychology Press.

O'Sullivan, P. and Ngau, O. (2014). 'Whistleblowing: a critical philosophical analysis of the component moral decisions of the act and some new perspectives on its moral significance'. Business Ethics: A European Review 23 (4), pp. 401-415. https : //doi .org/10.1111/beer. 12058.

Padilla, M. (19th March 2020). "It feels like a war zone': doctors and nurses plead for masks on social media'. The New York Times. URL: https : / www . nytimes . com /2020/03/19/us/hospitals-coronavirus-ppe-shortage.html.

Perlow, L. and Williams, S. (2003). 'Is silence killing your company?' Harvard Business Review 81 (5), pp. 52-58.

Preston, J. (11th June 2016). 'Laid-off Americans, required to zip lips on way out, grow bolder'. The New York Times.

URL: https://www .nytimes . com/2016/06/12/us/laid-off-americans-requir ed-to-zip-lips-on-way-out-grow-bolder.html.

Richtel, M. (7th April 2020). 'At the hospital, a face-off over face masks'. The New York Times. URL: https://www nytimes . com/2020/03/31/health/hospitals-co ronavirus-face-masks.html.

Roberson, T. (2020). 'On social change, agency and public interest: what can science communication learn from public relations?' JCOM 19 (02), Y01. https://doi.org/10.22323/2.19020401. 
Sengupta, S. (27th March 2020). 'Outrage and finger-pointing after a nurse dies'. The New York Times. URL: https: //www. nytimes . com/2020/03/26/nyregion/nu rse-dies-coronavirus-mount-sinai.html.

Servais, J. (6th April 2020). 'PeaceHealth sets up straw man of Dr. Lin'. Northwest Citizen. URL: https://nwcitizen. com/entry/peacehealth-sets-up-straw-ma $\mathrm{n}$-of-dr-lin.

Stoker, K. (2005). 'Loyalty in public relations: when does it cross the line between virtue and vice?' Journal of Mass Media Ethics 20 (4), pp. 269-287. https://doi.org/10.1207/s15327728jmme2004_4.

Thomas, R. G. (2020). 'Whistleblowing and power: a network perspective'. Business Ethics: A European Review. https://doi.org/10.1111/beer.12290.

U.S. Department of Health and Human Services Office of Inspector General (3rd April 2020). Hospital experiences responding to the COVID-19 pandemic, results of a national pulse survey March 23-27, 2020. OEI-06-20-00300. URL: https : // oig .hhs.gov/oei/reports/oei-06-20-00300.asp?utm_source=web\&utm_medium=w eb\&utm_campaign=covid-19-hospital-survey-04-06-2020.

Waddington, K. (2012). Gossip and organizations. New York, NY, U.S.A.: Routledge. https://doi.org/10.4324/9780203111789.

Watkins, S. (3rd April 2020). 'Silencing nurses and doctors will make the coronavirus worse'. Seattle Times.

URL: https://www . seattletimes . com/opinion/silencing-nurses-and-docto rs-will-make-the-coronavirus-crisis-worse/.

Yamada, D. C. (1998). 'Voices from the cubicle: protecting and encouraging private employee speech in the post-industrial workplace'. Berkeley Journal of Employment and Labor Law 19 (1), pp. 3-59. URL: https://www . jstor.org/stable/24050851.

Zhang, R., Li, Y., Zhang, A. L., Wang, Y. and Molina, M. J. (2020). ‘Identifying airborne transmission as the dominant route for the spread of COVID-19'. Proceedings of the National Academy of Sciences 117 (26), pp. 14857-14863. https://doi.org/10.1073/pnas. 2009637117.

Author

Karen Adkins. Professor of Philosophy, Regis University, Denver, CO. Has published Gossip, Epistemology, and Power (Palgrave, 2017), as well as articles in Social Epistemology, Hypatia, Teaching Philosophy, Global Discourse, among other journals. E-mail: kadkins@regis.edu.

\section{How to cite}

Adkins, K. (2020). 'Exit only: harms from silencing employee voice'. JCOM 19 (05), A03. https://doi.org/10.22323/2.19050203. 